\title{
Abstinence following Alcohol Drinking Produces Depression-Like Behavior and Reduced Hippocampal Neurogenesis in Mice
}

\author{
Jennie R Stevenson', Jason P Schroeder ${ }^{1,3}$, Kimberly Nixon ${ }^{1,4}$, Joyce Besheer', Fulton T Crews ${ }^{1,2}$ and \\ Clyde W Hodge ${ }^{*, 1,2}$
}

'Department of Psychiatry, Bowles Center for Alcohol Studies, Curriculum in Neurobiology, University of North Carolina at Chapel Hill, Chapel Hill, NC, USA; 'Department of Pharmacology, Bowles Center for Alcohol Studies, Curriculum in Neurobiology, University of North Carolina at Chapel Hill, Chapel Hill, NC, USA

\begin{abstract}
Alcoholism and depression show high degrees of comorbidity. Clinical evidence also indicates that depression that emerges during abstinence from chronic alcohol use has a greater negative impact on relapse than pre-existing depression. Although no single neurobiological mechanism can account for the behavioral pathologies associated with these devastating disorders, converging evidence suggests that aspects of both alcoholism and depression are linked to reductions in hippocampal neurogenesis. Here, we report results from a novel preclinical behavioral model showing that abstinence from voluntary alcohol drinking leads to the emergence of depressionlike behavior and reductions in neurogenesis. C57BL/6) mice were allowed to self-administer ethanol ( $10 \%$ v/v) vs $\mathrm{H}_{2} \mathrm{O}$ in the home cage for 28 days. Alcohol was then removed for I or 14 days, and mice were tested in the forced swim test to measure depression-like behavior. After 14 days, but not I day of abstinence from alcohol drinking, mice showed a significant increase in depression-like behavior. The significant increase in depression-like behavior during abstinence was associated with a reduction in proliferating cell nuclear antigen (PCNA) and doublecortin (DCX) immunoreactivity in the dentate gyrus of the hippocampus indicating that both the number of proliferating neural progenitor cells (NPC) and immature neurons were reduced, respectively. The number of NPCs that were labeled with bromo-deoxyuridine (BrdU) at the beginning of alcohol exposure was not altered indicating that survival of NPCs is not linked to abstinence-induced depression. Chronic treatment ( 14 days) with the antidepressant desipramine during abstinence prevented both the emergence of depression-like behavior and the reduction in hippocampal neurogenesis indicating that abstinence-induced depression is associated with structural plasticity in the hippocampus. Overall, the results of this study support the conclusion that profound functional (ie behavioral) and structural changes occur during abstinence from alcohol use and suggest that antidepressant treatment may alleviate some of these pathological neurobehavioral adaptations.

Neuropsychopharmacology (2009) 34, 1209-1222; do::10.1038/npp.2008.90; published online 18 June 2008
\end{abstract}

Keywords: alcohol drinking; abstinence; depression; neurogenesis; antidepressant

\section{INTRODUCTION}

Alcoholism and depression are two of the most costly and widespread neuropsychiatric disorders worldwide. In the United States, the prevalence of a lifetime history of

\footnotetext{
*Correspondence: Dr CW Hodge, Bowles Center for Alcohol Studies, Thurston-Bowles Building; CB No. 7178, University of North Carolina at Chapel Hill, Chapel Hill, NC 27599, USA, Tel: + I 9198434823 , Fax: + | 919966 5679, E-mail: chodge@med.unc.edu

${ }^{3}$ Present address: Department of Human Genetics, Emory University, Whitehead 301, 6I5 Michael Street, Atlanta, GA 30322, USA.

${ }^{4}$ Present address: Department of Pharmaceutical Sciences, University of Kentucky, 74I S Limestone, BBSRB B35I, Lexington, KY 40536, USA.

Received 10 January 2008; revised 15 May 2008; accepted 16 May 2008
}

depression in alcohol-dependent individuals has been reported to be about 42\% (Miller et al, 1996; Schuckit et al, 1997) but comorbidity rates from $5 \%$ to as high as $80 \%$ have been noted in some studies (Pettinati, 2004). Alcohol abuse and/or dependence are also associated with a two- to fourfold increase in depression rates (Grant, 1995; Kessler et al, 1997). Moreover, rates of depression are significantly elevated among people who seek treatment for alcoholism (Lynskey, 1998) and depressive symptoms are common in alcohol dependence and abstinence (Garbutt et al, 1999). When alcoholism and depression co-occur, relapse to alcohol use is more likely and remission from depression is less likely (Greenfield et al, 1998; Mueller et al, 1994).

Emerging evidence indicates that features of both alcoholism and depression may be mediated by changes in adult hippocampal neurogenesis (Crews and Nixon, 2003; Duman 
alcohol or water for 28 days using a two-bottle drinking procedure and were behaviorally tested after $1(n=12)$ or $14(n=12)$ days of abstinence; water-only controls $(n=12)$ had access to two bottles of water for 28 days and then were behaviorally tested one day later. Mice were returned to the vivarium after behavioral testing and brains were removed $24 \mathrm{~h}$ later (Figure 1a).

In the second set of experiments, mice were allowed 7 days to adapt to handling and the laboratory environment (Figure 1b). Mice were randomly assigned to the following treatment conditions: two groups of alcohol-drinking mice voluntarily consumed alcohol or water for 28 days using a two-bottle drinking procedure (see below); one group of water-only controls had access to two bottles of water for 28 days. Alcohol-drinking mice then received injections of either vehicle $(n=12)$ or desipramine ( $n=12$, see Drugs below) during a 14-day abstinence period. Water-only control mice received daily injections of either vehicle $(n=12)$ or desipramine $(n=12)$ in parallel to the alcohol-abstinent mice. Water-only mice that received vehicle injections served as a control for alcohol exposure and injection stress. In addition, this group allowed us to rule out potential effects of aging on neurogenesis. The first injection was given the same day that alcohol bottles were removed from the cages, so that the 14th injection occurred 13 days after removal of alcohol. Behavior of all mice was evaluated in the forced swim test 1 day after the final desipramine injection (Figure 1b). Desipramine was not administered on behavioral test days, to examine the effects of chronic, but not acute, antidepressant treatment. Animals were killed $24 \mathrm{~h}$ after behavioral testing (Figure $1 \mathrm{~b}$ ).

An additional experimental group was included in immunohistochemical studies in which animals were killed at the end of their 28th day of alcohol drinking ( 0 days of abstinence). This group was not included in behavioral studies to avoid potential confounding effects of acute alcohol.

\section{Two-Bottle Drinking Procedure}

During the 1-week period of acclimation and handling, water was the only fluid available. All fluids were presented in the home cage through $50 \mathrm{ml}$ plastic centrifuge bottles with stainless steel sipper tubes. Alcohol-drinking mice were then given access to one bottle of water and one bottle of alcohol $(10 \% \mathrm{v} / \mathrm{v})$ as previously described (Hodge et al, 1999). Animals were weighed and the fluid levels in the bottles were monitored to the nearest $0.5 \mathrm{ml}$ at $24-\mathrm{h}$ intervals to determine daily fluid intake ( $\mathrm{ml}$ and $\mathrm{g} / \mathrm{kg}$ ). The position (left-right) of the alcohol and water bottle was changed each day to control for side preferences. Mice were given access to alcohol for 28 days. Control animals had access to two bottles of water for the same duration (28 days). On day 23 of alcohol drinking, tail blood was collected and analyzed for blood alcohol level. On the final day of drinking, the alcohol solution-containing bottle was removed from the cages of alcohol drinkers, and one water bottle was removed from the cages of controls; thus, during abstinence only one bottle was on each cage.

\section{Blood Alcohol Determination}

Blood alcohol level was measured from tail vein blood samples taken between 2 and $3 \mathrm{~h}$ into the dark cycle as an index of alcohol intake. Individual blood samples (approximately $20 \mu \mathrm{l}$ ) were centrifuged and $5 \mu \mathrm{l}$ of plasma from each sample was used to determine alcohol concentration using an AM1 Alcohol Analyzer (Analox Instruments, Lunenburg, MA).

\section{Behavioral Testing}

Open-field locomotor activity and anxiety-like behavior. Mice were first tested for spontaneous locomotor activity and anxiety-like behavior (thigmotaxy) in brightly lit (500 lux) chambers $(28 \mathrm{~cm} \times 28 \mathrm{~cm})$ during 15 min sessions as described (Hodge et al, 2002). For assessment of activity in the center of the field, the chamber floor was divided post hoc into a center zone $(14 \times 14 \mathrm{~cm}$; center equidistant from all four walls of the chamber) and a periphery zone (the remaining area of the floor). Total horizontal distance (cm) traveled (locomotor activity) and time spent in the center zone (anxiety-like behavior) were calculated from the locomotor activity data. After each test session, the equipment was cleaned with acetic acid (2\%) to limit animal odors. Locomotor tests were conducted between 1100 and $1200 \mathrm{~h}$ (1-2 $\mathrm{h}$ into the dark cycle).

Depression-like behavior. Three hours after locomotor activity testing, depression-like behavior was assessed using the FST (Porsolt et al, 1977). Mice were placed in a $2000 \mathrm{ml}$ beaker containing $1300 \mathrm{ml}$ of water maintained at $23-25^{\circ} \mathrm{C}$ for $6 \mathrm{~min}$. Behavior was videotaped for later analysis by two trained observers who were blind to the treatment conditions. The duration of immobility during the last 4 min of the FST was measured during a single session as an index of depression-like behavior. Mice were considered immobile if they were completely still except for small movements of the paw made only to keep the mouse afloat, and not producing any noticeable propulsion of the mouse.

\section{Drugs}

Bromo-deoxyuridine (BrdU) (Sigma-Aldrich, St Louis, MO) $(300 \mathrm{mg} / \mathrm{kg}, 15 \mathrm{ml} / \mathrm{kg}$, dissolved in saline, i.p.), used here as a marker of surviving neural progenitor cells, was administered once a day for 3 days before the onset of alcohol drinking. Where indicated, mice were injected with desipramine-HCl (Sigma-Aldrich, St Louis, MO) $(15 \mathrm{mg} / \mathrm{kg}$, $10 \mathrm{ml} / \mathrm{kg}$, i.p. $)$ or vehicle $(0.9 \%$ saline, $10 \mathrm{ml} / \mathrm{kg}$, i.p. $)$ once per day for 14 days during abstinence. The antidepressant desipramine was used in this study because it has been shown to be highly effective (more so than fluoxetine) in the FST in C57BL/6J mice (Lucki et al, 2001). This particular dose of desipramine was selected based on its efficacy in the FST and its ability to produce hippocampal neuroadaptive changes (Lucki et al, 2001; Thome et al, 2000).

\section{Tissue Fixation and Sectioning}

Animals were deeply anesthetized with pentobarbital $(60 \mathrm{mg} / \mathrm{kg}, 10 \mathrm{ml} / \mathrm{kg}$, i.p.) and perfused transcardially with 
$0.1 \mathrm{M}$ phosphate-buffered saline (PBS) followed by $4 \%$ paraformaldehyde. The brains were removed from the skull and placed in the same fixative solution for at least $24 \mathrm{~h}$ before being washed with PBS and sliced on a Leica VT $1000 S$ vibrating microtome into $40 \mu \mathrm{m}$ sections. The free-floating sections were stored in cryoprotectant at $-20 \mathrm{C}$ until immunohistochemistry was performed.

\section{Immunohistochemistry}

Tissue was washed in PBS, and then treated with $0.6 \%$ hydrogen peroxide to block endogenous peroxidase activity. Tissue was incubated for $1 \mathrm{~h}$ in a blocking solution (3\% horse serum, $0.1 \%$ Triton-X, $0.1 \mathrm{M}$ PBS) before incubation in the primary antibody. Sections were incubated in the antiproliferating cell nuclear antigen antibody (EMD Biosciences Inc., San Diego, CA; dilution 1:400) overnight at $4{ }^{\circ} \mathrm{C}$ or in the anti-doublecortin antibody (Santa Cruz Biotechnology Inc., Santa Cruz, CA; dilution: 1:1000) for $48 \mathrm{~h}$ at $4{ }^{\circ} \mathrm{C}$. The following day, tissue sections were rinsed in PBS before incubation in the appropriate secondary antibody (Vector Laboratories, CA) for $1 \mathrm{~h}$. Tissue was then processed with avidin-biotin complex (Vector $A B C$ kit, Vector Laboratories, CA) and immunoreactivity was visualized with DAB (Polysciences Inc., PA). Tissue sections were then rinsed in PBS and, in the case of proliferating cell nuclear antigen (PCNA) immunohistochemistry, counterstained with toluidine blue before the sections were mounted onto slides.

For BrdU immunohistochemistry, tissue was prepared according to the method of Nixon and Crews (2002). Tissue was washed in PBS, and then treated with $0.6 \%$ hydrogen peroxide to block endogenous peroxidase activity. Next, tissue was incubated in $50 \%$ formamide $/ 2 \times$ SSC for $2 \mathrm{~h}$ at $65^{\circ} \mathrm{C}$, then in $2 \mathrm{~N} \mathrm{HCl}$ for $1 \mathrm{~h}$ at $37^{\circ} \mathrm{C}$. After neutralizing in $0.1 \mathrm{M}$ boric acid, tissue was rinsed in PBS, then incubated overnight at $4{ }^{\circ} \mathrm{C}$ in primary antibody (anti-BrdU: Accurate Chemical and Scientific Corp., NY; dilution 1:400). The following day was performed as described above for PCNA immunohistochemistry. Antibody dilutions were chosen based on dilution curves, and antibody specificity was verified secondary only to controls in all immunohistochemical assays.

\section{Analysis of immunohistochemistry}

For BrdU and PCNA immunohistochemistry, immunopositive cells in the dentate gyrus were counted manually with an oil immersion lens (Plan Apo $\times 60$ oil; numerical aperture, 2.0; Olympus Optical, Melville, NY). Profile counting methodology was used as it has previously been shown that profile counting and stereological estimations show identical results in percentage change (Crews et al, 2004). Moreover, stereology may not be appropriate for quantifying BrdU + cells, because they are not homogeneously distributed throughout the dentate (Popken and Farel, 1997). Cell counts are expressed as the number of immunopositive cells per dentate gyrus section. For doublecortin immunohistochemistry, image analysis software (Bioquant Nova Advanced Image Analysis; R\&M Biometric, Nashville, TN) was used to measure optical densitometry of the staining. Densitometry measurements are divided by the area of the section and expressed as pixels $/ \mathrm{mm}^{2}$. Every sixth section within stereotaxic range from Bregma $-1.46 \mathrm{~mm}$ to Bregma $-2.54 \mathrm{~mm}$ (Paxinos and Franklin, 2001) was analyzed to generate an average cell count or pixel density for each subject. Experimenter performing immunohistochemical analyses was blind to the treatment condition of the subjects. Desitometry analyses were repeated during a subsequent Bioquant session to ensure that results replicated.

\section{Immunofluorescence}

Triple-label confocal microscopy was performed according to Nixon and Crews (2004). The colocalization of BrdU with neuronal-specific nuclear protein $(\mathrm{NeuN})$ or glial fibrillary acidic protein (GFAP) proteins was used to characterize the fate of surviving NPCs. Tissue was washed in PBS, then incubated in a blocking buffer. Tissue was then incubated in a solution containing primary antibodies (rat anti-BrdU, Accurate, Westbury, NY; dilution 1:400; mouse anti-NeuN, Chemicon, Temecula, CA; dilution 1:500; rabbit anti-GFAP, Dako, Glostrup, Denmark; dilution 1:2000). The following day, tissue was rinsed in PBS, and then incubated in the dark with fluorescent-coupled secondary antibodies appropriate for each primary antibody. Tissue was then rinsed in PBS and mounted onto slides, taking care to protect the sections from the light. Slides were coverslipped using ProLong Anti-Fade reagent (Molecular Probes, OR).

\section{Visualization and Analysis of Immunofluorescence}

Triple-label immunofluorescence was visualized with a Zeiss (Oberkochen, Germany) Axiovert LSM510 confocal microscope on multitrack setting with a water immersion lens (C-Apochromat $\times 40 / 1.2 \mathrm{~W}$ corr). Colocalization was confirmed by confocal microscopy optimized for the analysis of tissue sections. For each subject, 50 BrdU-labeled cells were analyzed for colocalization with GFAP or NeuN. Percentages of BrdU-labeled cells that colabeled with each cell type were determined. The 50 cells were selected from several fields in a minimum of five tissue sections. Z-plane section images $(512 \times 512$ pixels $)$ were collected at $<1 \mu \mathrm{m}$ thickness and then analyzed using LSM Image Examiner software (Zeiss). The criteria for colabeling included appropriate morphology and more than two Z-plane images of co-positive staining.

\section{Statistical analyses}

In the first set of experiments, between subjects one-way analysis of variance (ANOVA) were used to analyze changes in behavior and immunohistochemistry. Post hoc Dunnett's tests were conducted to determine if treated groups were different from control. In the second set of experiments, between subjects two-way ANOVA were used to analyze changes in behavior and immunohistochemistry. Post hoc Tukey tests were used to determine between-group differences. Statistical significance was always defined as $p<0.05$. All statistical procedures were conducted with SigmaStat v3 software (Systat Software Inc., San Jose, CA). 


\section{RESULTS}

Abstinence following Alcohol Drinking is Associated with an Increase in Depression-Like Behavior

To determine if abstinence following alcohol drinking is associated with changes in depression-like behavior, FST performance of water-only control mice was compared to mice that consumed alcohol for 28 days followed by 1 or 14 days of abstinence.

Alcohol exposed mice voluntarily consumed average of $17.8 \pm 1.0 \mathrm{~g} / \mathrm{kg} /$ day of alcohol $(10 \% \mathrm{v} / \mathrm{v})$ in the home cage for 28 days, which resulted in average peak blood alcohol levels of $112.8 \pm 7.4 \mathrm{mg} / \mathrm{dl}$. Total fluid intake did not differ between water- and alcohol-exposed mice (data not shown). One-way ANOVA on FST data showed a significant main effect of exposure condition $(\mathrm{F}(2,33)=3.53, p<0.05)$ that was due to a $36 \%$ increase in immobility following 14 days of abstinence as compared with water-only controls $(p<0.05$, Dunnett's test). No significant increase in immobility was evident 1 day after cessation of alcohol drinking ( $p>0.05$, Dunnett's test; Figure 2a). These data show for the first time that alcohol drinking, followed by abstinence, leads to an emergent increase in depression-like behavior.

\section{Abstinence following Alcohol Drinking is Associated with a Transient Increase in Anxiety-Like Behavior}

Anxiety-like behavior was also evaluated by measuring the amount of time spent in the center of an open field immediately prior to the FST. A one-way ANOVA comparing water mice with mice that drank alcohol for 28 days followed by 1 or 14 days of abstinence demonstrated a significant difference in time spent in the center of an open field $(\mathrm{F}(2,33)=13.33, p<0.001)$ (Table 1). A significant decrease in the amount of time spent in the center of an open field was evident in mice after 1 day of abstinence $(p<0.05$, Dunnett's test) but not 14 days of abstinence ( $p>0.05$, Dunnett's test). These data indicate a temporary increase in anxiety-like behavior after 1 day of abstinence that disappears by 15 days of abstinence. Overall locomotor activity was analyzed 1 or 14 days after the removal of alcohol access. A one-way ANOVA showed an overall difference in locomotor activity $(\mathrm{F}(2,33)=4.26, p=0.02)$ (Table 1); however, post hoc comparisons revealed that neither alcohol treatment differed from control $(p<0.05$, Dunnett's test). These data show that differences observed in depression-like and anxiety-like behavior were not attributable to alterations in motor ability.

\section{Survival and Differentiation of Neural Progenitor Cells}

Survival of hippocampal NPCs is reduced by exposure to forced alcohol liquid diet in rats that causes high blood alcohol levels (Herrera et al, 2003). However, the effects of abstinence following chronic voluntary drinking on the survival of NPCs are not known. BrdU was injected before the onset of drinking to assess the number of dividing cells that survived until the brains were removed. There was no significant difference $(\mathrm{F}(2,29)=1.67, p=0.207)$ in the number of BrdU-labeled cells per dentate gyrus that remained after 1 or 14 days of abstinence following chronic

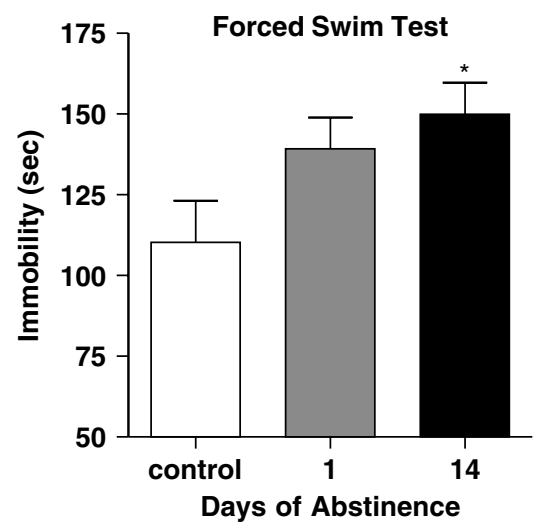

Figure 2 Abstinence from alcohol drinking increases depression-like behavior. Mean immobility (sec) in the forced swim test (FST) increased as a function of days of abstinence from alcohol drinking as compared with water-drinking controls. Data are plotted as mean \pm SEM from $n=12$ mice in each condition. Please note that the $y$ axis origin is $50 \mathrm{~s}$. *Significantly different from water-drinking control, $p<0.05$ (Dunnett's $t$-test).

Table I Anxiety-like Behavior and Locomotor Activity Associated with Abstinence following Voluntary Alcohol Drinking

\begin{tabular}{lcc}
\hline Abstinence (days) & Time in center (sec) & Distance traveled (cm) \\
\hline Control & $190.2 \pm 17.6$ & $4668.9 \pm 245.6$ \\
| & $90.75 \pm 10.2 *$ & $5402.8 \pm 242.9$ \\
|4 & $147.9 \pm 12.1$ & $4503.5 \pm 204.7$
\end{tabular}

Anxiety-like behavior (time in center) and locomotor activity (distance traveled). *Significantly different from control, $p<0.05$, Dunnett's test.

voluntary drinking compared with water-only controls (Figure 3a). Representative images of BrdU immunohistochemistry in the dentate gyrus are shown (Figure $3 b$ ). These results indicate that neither short-term nor protracted abstinence affects the survival of NPCs in this model of alcohol consumption. Although no change in the number of surviving BrdU-labeled cells was evident, the number of surviving NPCs that became neurons or glia could have been affected. Triple-label immunofluorescence, however, revealed that the remaining BrdU-labeled cells underwent neuronal and glial differentiation at the expected rates (Nixon and Crews, 2004). Of the BrdU-labeled cells analyzed from alcohol drinkers $(n=50$ cells/animal) and water-only controls ( $n=50$ cells/animal), 89 and $92 \%$ colocalized with NeuN in the dentate gyrus, respectively. Representative immunofluorescence in the dentate gyrus is shown (Figure $3 \mathrm{c}$ and $\mathrm{d}$ ). These data indicate chronic voluntary drinking does not affect the percentage of neuronal differentiation of surviving NPCs.

\section{Proliferation of Neural Progenitor Cells}

Although survival of NPCs was unchanged by voluntary alcohol drinking and abstinence, it is possible that other stages of neurogenesis, such as proliferation, were affected. Previous studies have demonstrated biphasic alterations in NPC proliferation associated with alcohol exposure and 
a

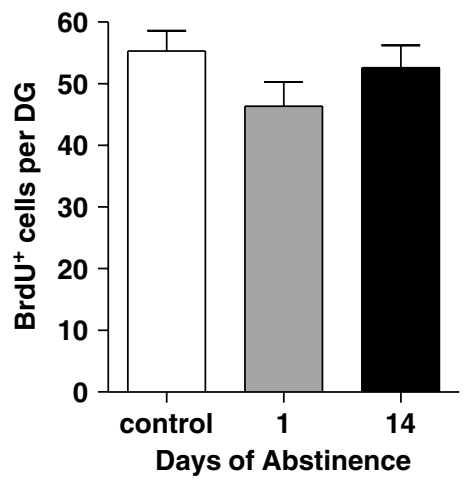

b

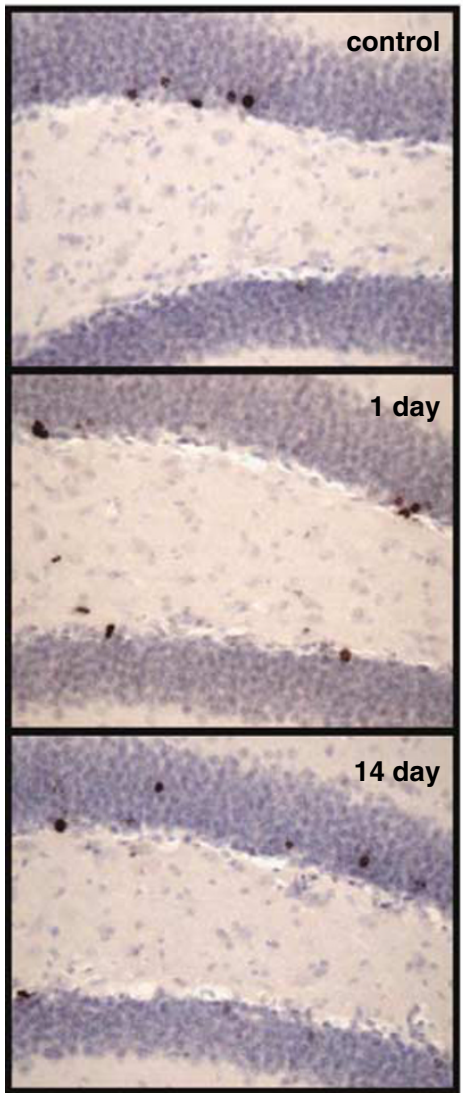

C

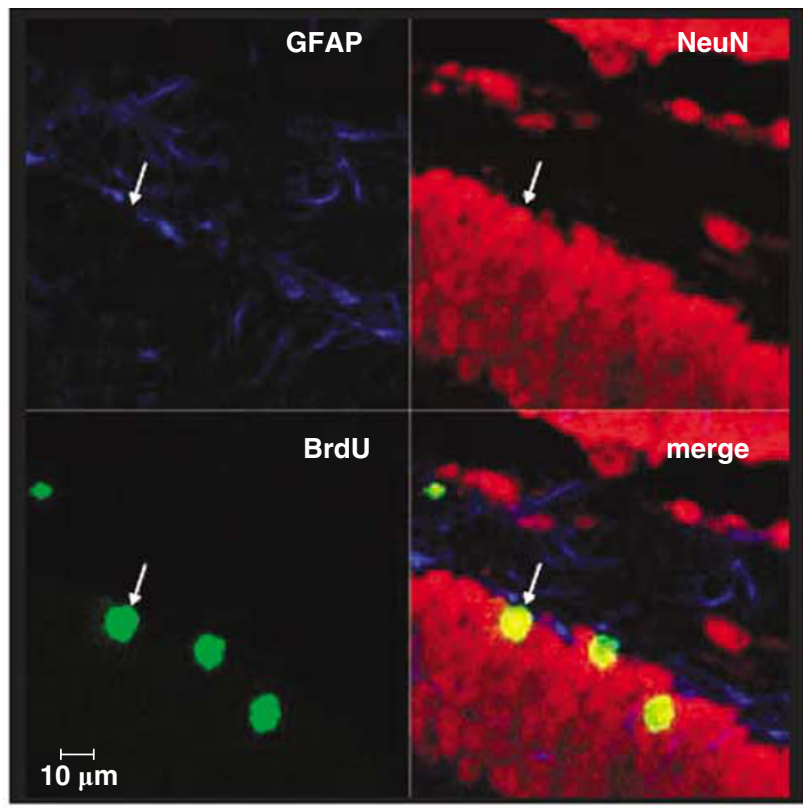

d

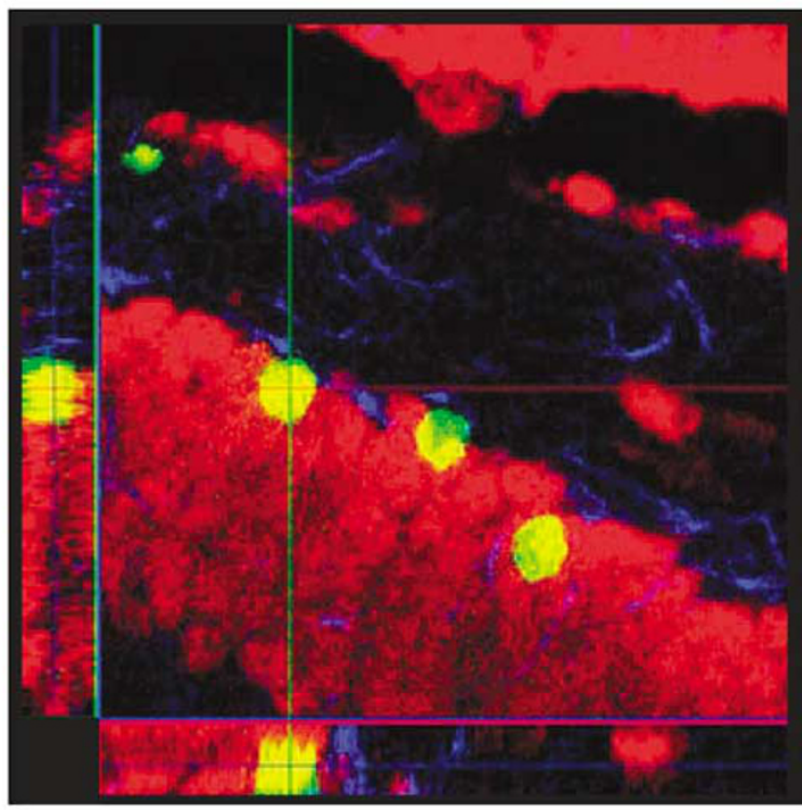

Figure 3 No changes in survival of NPCs. (a). The mean number of BrdU-labeled cells that survive is unchanged in the dentate gyrus following voluntary drinking and I- or I4-day abstinence. (b) Representative images showing BrdU-labeled cells in the dentate gyrus from control, I day of abstinence, and 14 days of abstinence. (c) Triple-label immunofluorescence was used to evaluate differentiation of surviving NPCs. A representative dentate gyrus is shown. GFAP-labeled glial cells are shown in blue, NeuN-labeled neuronal nuclei are shown in red, BrdU-labeled cells are shown in green. (d) An orthogonal view of a representative cell showing colocalization of BrdU and NeuN. The number of surviving BrdU-labeled cells that colabeled with the neuronal marker NeuN was unchanged in ethanol-treated brains. Data are plotted as mean \pm SEM from $n=9-12$ mice in each condition.

withdrawal (Aberg et al, 2005; Crews et al, 2004; He et al, 2005; Nixon and Crews, 2002). To determine if abstinence from chronic drinking (and depression-like behavior) is associated with changes in NPC proliferation, serial sections of hippocampus were immunolabeled with PCNA, which is a cell cycle-specific nuclear protein belonging to the replication complex that permits DNA synthesis needed for G1 to S transition(Krude, 1999; Yew et al, 2001) and correlates with the proliferative state of cells (Celis et al, 1987). One-way ANOVA comparing PCNA cell counts from alcohol drinking mice to water-only control mice revealed a main effect $(\mathrm{F}(3,36)=6.5, p=0.001)$. Follow up comparisons showed that abstinence following alcohol drinking for 14 days produced a significant decrease in NPC proliferation ( $p<0.05$, Dunnett's test) as indexed by the number of PCNA-labeled cells, while 0 and 1 day of abstinence did not produce a change in PCNA immunoreactivity (Figure 4a). Representative photomicrographs illustrating PCNA immunoreactivity in the dentate gyrus are shown in Figure 4c. These results indicate that 14 days of abstinence following voluntary drinking leads to a decrease in the proliferation of NPCs in the dentate gyrus. 
a

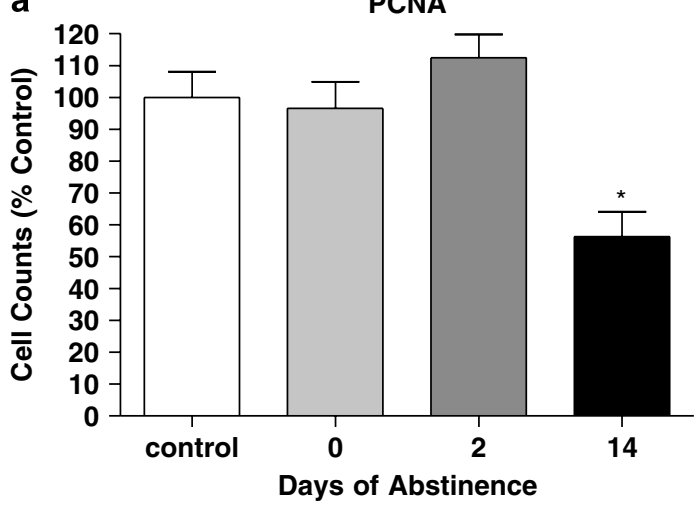

C

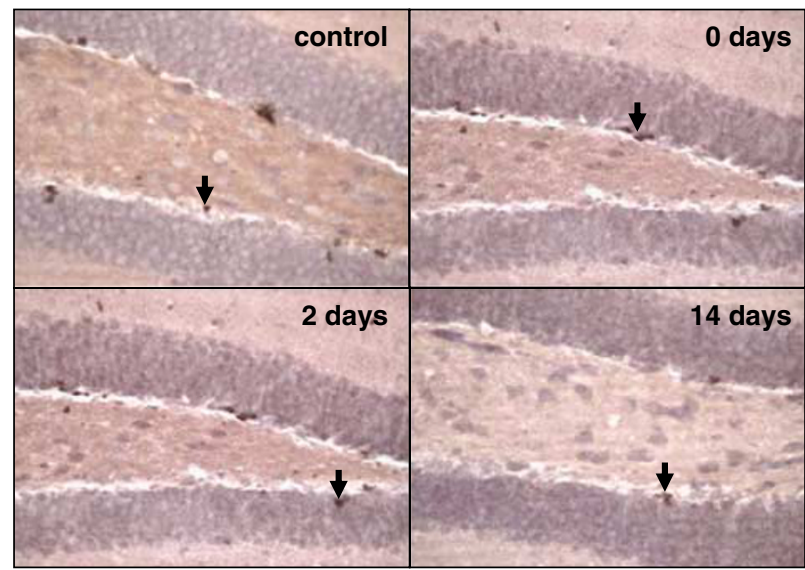

b

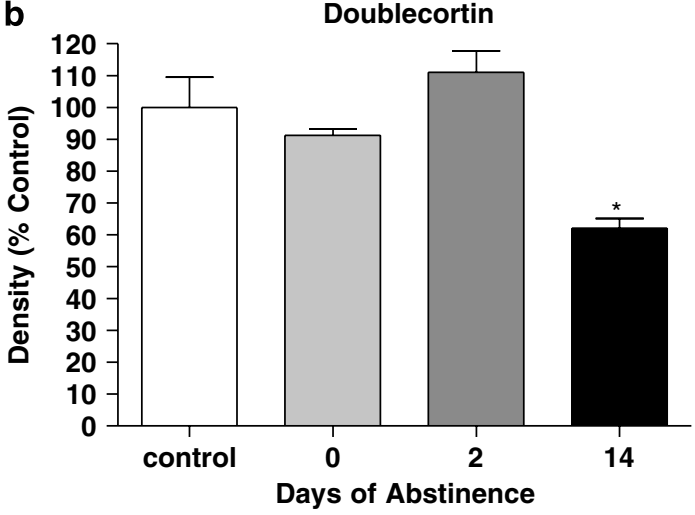

d

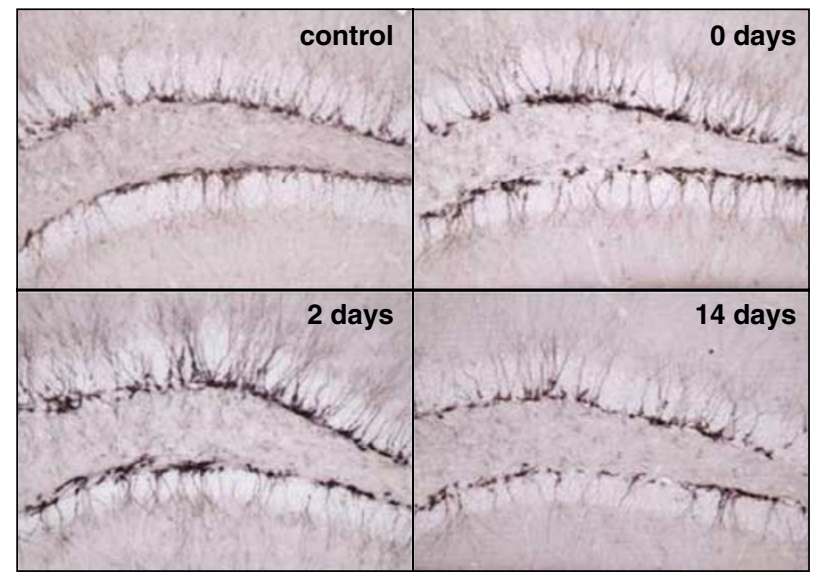

Figure 4 Abstinence from alcohol reduces adult hippocampal neurogenesis. PCNA and DCX immunohistochemistry. (a) Relative change in PCNA immunoreactivity (IR) in the dentate gyrus showing a reduction in NPC proliferation as a function of 0 , I, or I4 days of abstinence from alcohol drinking. (b) Relative decrease in DCX IR showing that the number of new neurons in the dentate gyrus is reduced as a function of abstinence from alcohol drinking. (c and d) Representative images of dentate gyrus from control, 0 days, 2 days, and 14 days of abstinence for PCNA IR (c) and DCX IR (d). Arrow heads point to representative PCNA-labeled cells. Mean data were obtained from averaging results from four tissue sections per mouse and plotted as percent change from water-drinking control. *Significantly different from water-drinking control, $p<0.05$ (Dunnett's $t$-test).

\section{Number of Immature Neurons}

Another approach to assessing neurogenesis is to examine the number of immature neurons in the dentate gyrus. Doublecortin immunohistochemistry can be used to determine the density of cells in the hippocampus that have proliferated, survived, differentiated into neurons, and begun to develop neurites (Couillard-Despres et al, 2005; Rao and Shetty, 2004). The main effect was revealed by a one-way ANOVA comparing alcohol-drinking animals with water-only controls $(\mathrm{F}(3,40)=8.2, p=0.001)$. Similar to results from PCNA immunohistochemistry, the density of doublecortin immunoreactivity was significantly decreased following 14 days $(p<0.01$, Dunnett's test), but not 0 or 1 day of abstinence following alcohol drinking relative to control (Figure 4b). Representative photomicrographs illustrating DCX immunoreactivity in the dentate gyrus are shown in Figure 4d. These data suggest that the number of new neurons in the dentate gyrus is reduced following 14 days of abstinence following voluntary drinking.

\section{Antidepressant Treatment during Abstinence}

To determine if the emergence of depression-like behavior during abstinence can be prevented by administration of antidepressant medication, mice were given a single injection of desipramine each day for 14 days beginning the day alcohol was removed from the home cage. The day after the last desipramine injection, mice were tested in the FST. Desipramine was also used here to validate that the increase in immobility in the FST was a depression-related behavior. Results indicated that chronic desipramine treatment prevented the emergence of depression-like behavior in mice that were treated with the antidepressant during 2 weeks of abstinence following chronic drinking. Antidepressant treatment had no effect on the behavior of mice with no history of drinking. A two-way ANOVA found a significant interaction between alcohol drinking history and antidepressant treatment $(\mathrm{F}(1,41)=9.74, p=0.003)$; there was no main effect of alcohol or desipramine alone. Post hoc multiple comparison procedures showed that immobility was increased in ethanol drinking mice relative to water controls under the vehicle condition $(p=0.007$, Tukey test), indicating that abstinence following chronic drinking was associated with increased depression-like behavior. Within ethanol-drinking mice, desipramine treatment significantly decreased immobility in the FST $(p=0.008$, Tukey test), demonstrating that desipramine prevents increases in depression-like behavior following abstinence from chronic drinking (Figure 5a). Moreover, 


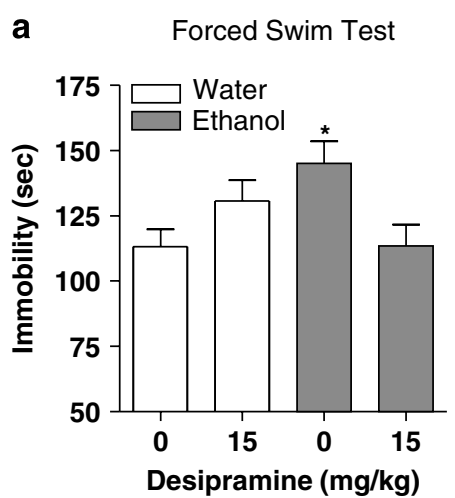

d

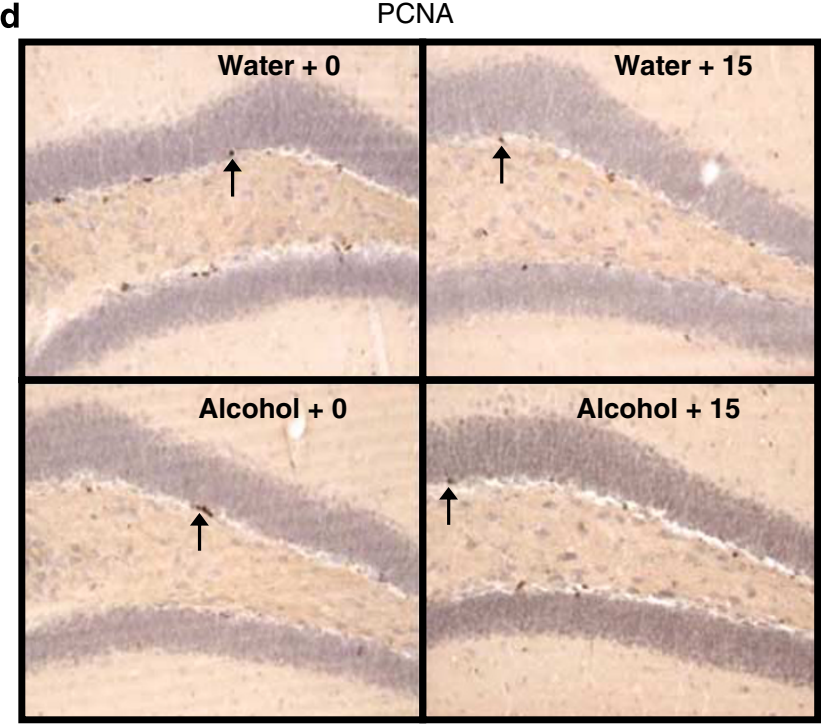

b

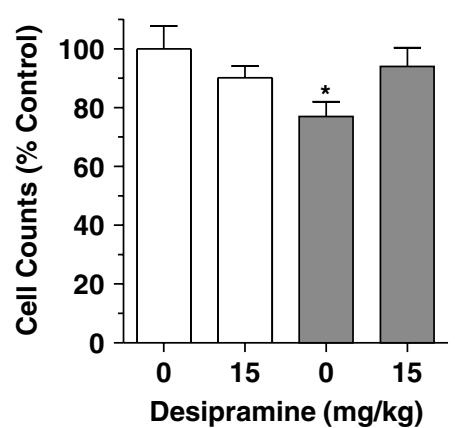

c

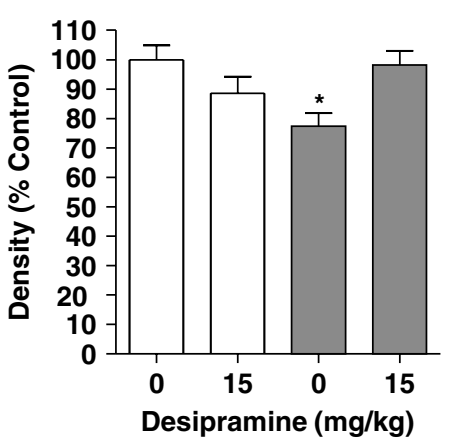

e

Doublecortin

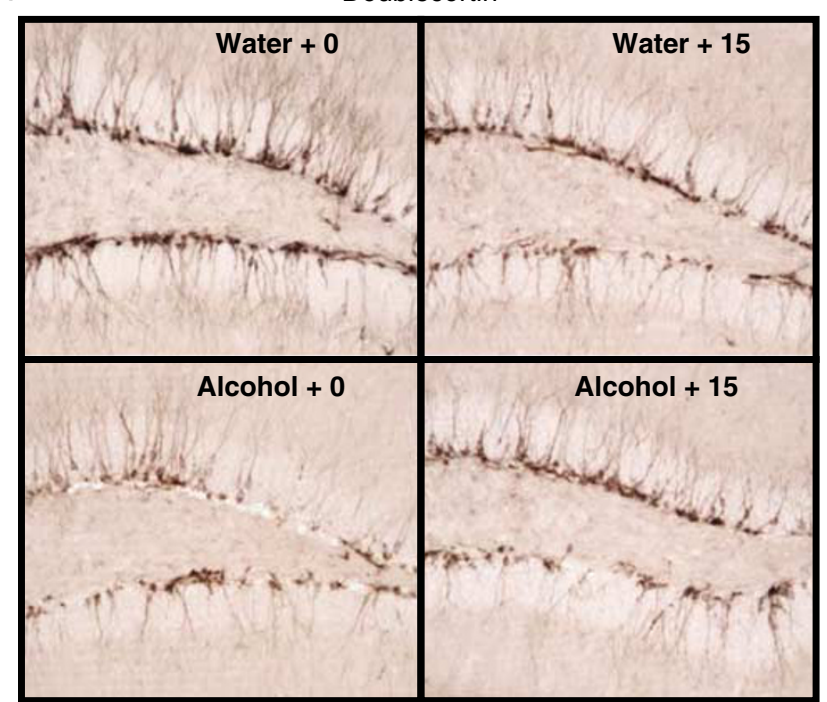

Figure 5 Desipramine treatment prevents abstinence-induced changes in depression-like behavior and neurogenesis. (a) Abstinence-induced increase in immobility (sec) in the forced swim test (FST) was completely blocked by treatment with desipramine during 14 days of abstinence $(n=12$ per group). Please note that the $y$ axis origin is $50 \mathrm{~s}$. *Significantly different from water-drinking mice that received vehicle (desipramine, $0 \mathrm{mg} / \mathrm{kg}$ ), $p=0.007$, and significantly different from ethanol- $15 \mathrm{mg} / \mathrm{kg}, p=0.008$ (Tukey test). (b) Desipramine treatment ( 14 days) prevented the abstinence-induced decrease in PCNA immunoreactivity in the dentate gyrus ( $n=12$ per group). *Significantly different from water-drinking mice that received vehicle (desipramine, $0 \mathrm{mg} / \mathrm{kg}$ ), $p=0.012$, (Tukey test). (c) Abstinence-induced reduction in DCX density was completely blocked by desipramine during 14 days of abstinence ( $n=12$ per group). *Significantly different from water-drinking mice that received vehicle (desipramine, $0 \mathrm{mg} / \mathrm{kg}$ ), $p=0.004$, and significantly different from ethanol- $15 \mathrm{mg} / \mathrm{kg}, p=0.005$ (Tukey test). Mean \pm SEM data for PCNA and DCX IR were obtained by averaging results from four tissue sections per mouse and plotted as percent change from water- $0 \mathrm{mg} / \mathrm{kg}$ controls. ( $\mathrm{d}$ and e) Representative images of dentate gyrus of PCNA IR (d) and DCX IR (e) from water and alcohol exposed mice that received Desipramine $(0$ or $15 \mathrm{mg} / \mathrm{kg}$ ) during the 14 -day abstinence period. Arrow heads point to representative PCNA-labeled cells.

alcohol-exposed mice that received desipramine treatment did not differ from water controls, indicating that the depression-like behavior that emerged during abstinence was fully blocked by the antidepressant desipramine.

Although studies have indicated that increasing neurogenesis may be a mechanism by which antidepressants produce their behavioral effects, we tested the ability of desipramine to block the decrease in neurogenesis associated with the emergence of depression-like behavior following 2 weeks of abstinence from chronic drinking. Immunohistochemical analyses of PCNA and DCX expression were performed to measure proliferation of NPCs and the number of immature neurons, respectively, 14 days after cessation of chronic drinking. Two-way ANOVA revealed no main effect of alcohol drinking or antidepressant treatment alone on the number of PCNAlabeled cells. Importantly, however, there was a significant interaction between alcohol drinking history and desipramine treatment $(\mathrm{F}(42,1)=4.71, p=0.036)$. Post hoc multiple comparisons (Tukey test) showed that the interaction was because of a significant reduction in the number of PCNA-labeled cells in alcohol drinking mice as compared with water controls in the vehicle condition $(p=0.012$, Figure 5b). The number of PCNA-positive cells following desipramine treatment was not different from water controls (Figure 5b). These data indicate that abstinence following chronic drinking decreases the number of proliferating cells in the dentate gyrus, and that this decrease is blocked by administration of desipramine during the abstinence period. Similarly, a two-way ANOVA found only a significant interaction between alcohol-drinking history and antidepressant treatment on DCX density $(\mathrm{F}(41,1)=$ 10.3, $p=0.003)$. As shown in Figure 5c, DCX density was reduced in alcohol-exposed mice within the vehicle 
condition as compared with water controls $(p=0.004$, Tukey test). Also, desipramine blocked the reduction in DCX density in alcohol-exposed mice $(p=0.005$, Tukey test). Representative photomicrographs illustrating PCNA and DCX immunoreactivity in the dentate gyrus are shown in Figure $5 \mathrm{~d}$ and e, respectively. Taken together, these data suggest that abstinence following chronic drinking leads to decreased neurogenesis in the dentate gyrus, and that desipramine treatment during abstinence prevents this decrease.

\section{DISCUSSION}

Clinical studies have noted high degrees of comorbidity between alcoholism and depression (Pettinati, 2004) and shown that depression that emerges during abstinence increases the likelihood of relapse (Hasin et al, 2002). Although little is known about the factors that promote this comorbidity, converging evidence implicates reductions in hippocampal neurogenesis as a mechanism that may underlie pathologies associated with both alcoholism and depression (Nixon, 2006; Warner-Schmidt and Duman, 2006). In this study, we show that depression-like behavior is increased during abstinence following voluntary alcohol drinking in mice. This behavioral pathology is associated with a reduction in hippocampal neurogenesis and treatment with the antidepressant desipramine restores the behavior and measurements of neurogenesis to normal levels. From these results, we propose that reduced hippocampal neurogenesis reflects a neuroadaptive process that underlies depression-like behavior that emerges during abstinence following alcohol drinking.

Though alcoholism is commonly associated with human depression, a functional relationship between alcohol consumption and depression-like behavior in a preclinical model has not been demonstrated previously. Using a novel mouse behavioral model, this study establishes an important link between abstinence following alcohol drinking and depression. In mice that voluntarily consumed alcohol for 28 days, increased depression-like behavior as measured by the FST was evident 14 days after alcohol was removed from the home cage. Although FST performance showed a trend after 1 day of abstinence, this increase in depression-like behavior was not significantly different from water controls. This suggests that the depression-like behavior was dissociated from any immediate effects of alcohol exposure or withdrawal. Further, the absence of reductions in overall locomotor activity suggests that the voluntary alcohol drinking procedure did not produce dependence (Pohorecky, 1976). Overall, these results suggest that neuroadaptive changes that occur during protracted abstinence following alcohol drinking lead to the emergence of depression-like behavior, even in moderate drinkers.

In addition to identifying the emergence of depressionlike behavior during protracted abstinence, the results of this study complement numerous investigations that have established a link between alcohol withdrawal and anxiety. For example, withdrawal from alcohol liquid diet, chronic injections, vapor exposure, or consumption from a single drinking bottle increase anxiety-like behavior in mice that persists for up to $48 \mathrm{~h}$ after alcohol exposure (Costall et al,
1988; Joshi et al, 2005; Kliethermes et al, 2004; Prediger et al, 2006; Sparta et al, 2007). Similar results have been obtained in rat models showing increased anxiety-like behavior during acute and early withdrawal from an alcohol liquid diet (Baldwin et al, 1991; Moy et al, 1997; Pandey et al, 1999; Rassnick et al, 1993). In the present study, we observed increased anxiety-like behavior in non-dependent mice 1 day after voluntary alcohol drinking as measured by an open-field thigmotaxy assay. Alcohol-exposed mice did not differ from water controls when anxiety-like behavior was measured after 2 weeks of abstinence. Accordingly, other data show that withdrawal from alcohol vapor increases anxiety-like behavior in rats during acute $(8 \mathrm{~h})$ withdrawal but the effect dissipates by 2 weeks (Zhao et al, 2007). However, studies have reported increased anxietylike behavior at 4 (Rasmussen et al, 2001) and 12 weeks (Zhao et al, 2007) after withdrawal from alcohol liquid diet or vapor exposure, respectively. Together, these and other data (reviewed by (Kliethermes, 2005) suggest that anxiety is a prominent feature of abstinence that may dissipate or cycle over time. Importantly, we found no evidence of increased anxiety-like behavior after 2 weeks of abstinence when depression-like behavior emerged, which suggests a time-dependent dissociation of these behavioral pathologies during abstinence.

A key finding of this preclinical study is that chronic treatment with the antidepressant desipramine during abstinence completely blocked the emergence of abstinenceinduced depression as measured by the FST in mice. Although the FST is most widely used as a behavioral screen for antidepressant efficacy, previous studies have also demonstrated that factors associated with human depression including chronic stress, inescapable stress, dysregulated monoamine function, and elevated glucocorticoids produce immobility in the FST (Hwang et al, 1999; Johnson et al, 2006; Plaznik et al, 1988; Prince and Anisman, 1984). The efficacy of desipramine validates the FST as a measure of depression in the present study. Importantly, the dose of desipramine used had no effect on behavior in the FST in water-only control mice. Furthermore, the prevention of depression-like behavior with desipramine, a tricyclic antidepressant, suggests that abstinence following chronic drinking may lead to dysregulation of noradrenergic and other monoaminergic systems, and that desipramine may prevent this dysregulation. Additional mechanistic studies are required to test this hypothesis.

While the effectiveness of antidepressants in treating depression is well validated, potential efficacy of these compounds in the treatment of alcoholism needs further study. There are only a limited number of well-controlled clinical studies on the efficacy of antidepressant use for alcoholics (Ostacher, 2007). Clinical studies have demonstrated that antidepressants are effective in reversing depression comorbid with alcoholism, and have shown modest success in preventing relapse (Le Fauve et al, 2004). As mentioned above, depression that occurs during abstinence has been linked to an increased risk of relapse (Hasin et al, 2002). When taken together with the present results, these findings suggest that antidepressant treatment that begins concurrently with cessation of drinking may be helpful in preventing the emergence of abstinence-related depression in the clinic. In addition, the beneficial effect of 
antidepressant treatment during abstinence provides further support for the conclusion that depression-like behavior may be functionally linked to abstinence-induced neuroadaptive changes.

The concept of adult neurogenesis has provided a new framework (eg the idea of structural plasticity) for understanding neuroadaptive changes in the adult brain, which extends prevailing theories that regard changes in synaptic efficacy (Hebb, 1949) as a solitary mechanism of neuroplasticity (Gage, 2002). Accumulating evidence now indicates that NPCs exist in a variety of mammalian brain regions where they give rise to new neurons, astrocytes, and oligodendrocytes throughout life (for a recent review see (Ming and Song, 2005)). Neurogenesis in the adult brain is a dynamic process that can be influenced by internal and external events that also influence behavior (for reviews see (Carlezon et al, 2005; Crews and Nixon, 2003; Duman et al, 1999; Gage, 2002; Henn and Vollmayr, 2004; Kempermann, 2002; Ming and Song, 2005). In general, evidence suggests that new neurons in the adult brain contribute to synaptic plasticity (Snyder et al, 2001), as well as the general ability of the organism to adapt to changing circumstances (Kempermann, 2002). Thus, neurogenesis is a structural event that may have functional consequences. Indeed, emerging evidence suggests that hippocampal neurogenesis may be functionally linked to stress and mood disorders (Dranovsky and Hen, 2006; Malberg and Blendy, 2005; Mirescu and Gould, 2006; Warner-Schmidt and Duman, 2006) cf. (Henn and Vollmayr, 2004).

Generation of functional new neurons by neurogenesis requires proliferation, differentiation, and survival of NPCs. In this study, we sought to determine if abstinence following voluntary alcohol drinking (and depression-like behavior) is associated with changes in adult hippocampal neurogenesis. To address this goal, serial sections of hippocampus were immunolabeled for PCNA, which labels proliferating cells. Results showed that 14 days of abstinence following alcohol drinking was associated with a $40 \%$ reduction in the number of PCNA-positive cells (cells in the process of proliferating) in the dentate gyrus as compared with wateronly control mice. Abstinence from alcohol drinking was also associated with a $40 \%$ reduction in immunoreactivity for DCX, which is a protein expressed by new cells that are in the process of differentiating into mature neurons. However, no reductions in PCNA or DCX immunoreactivity were observed at 0 or 2 days after alcohol indicating that the reduction in proliferating and differentiating NPCs emerged during protracted abstinence. These results indicate that abstinence-induced depression-like behavior in mice is associated with a concomitant reduction in hippocampal neurogenesis.

In contrast to the effect of protracted abstinence, we found no effect of 28 days of voluntary alcohol drinking, or short-term abstinence (2 days), on adult hippocampal neurogenesis (Figure 4b). Several studies have demonstrated that exposure to high doses of alcohol has a detrimental effect on adult hippocampal neurogenesis. For example, exposure to alcohol through binge injection or forced liquid diet models in rats produces significant decreases in proliferating NPCs and differentiating neurons (He et al, 2005; Nixon and Crews, 2002). In mouse models of voluntary alcohol drinking, high dose intake ( $>25 \mathrm{~g} / \mathrm{kg} /$ day) is also associated with a profound decrease (Crews et al, 2004), whereas lower dose intake (6 g/ $/ \mathrm{kg} /$ day) is associated with an increase in NPC proliferation (Aberg et al, 2005). In the present study, we found that $17-18 \mathrm{~g} / \mathrm{kg} /$ day of voluntary alcohol intake produced no change in proliferating or differentiating NPCs in the dentate gyrus in mice. Together these studies suggest that alcohol produces dosedependent effects on hippocampal neurogenesis.

Emerging studies have also shown that exposure to high doses of alcohol through binge injection or liquid diet reduces NPC survival in rats (He et al, 2005; Herrera et al, 2003; Nixon and Crews, 2002). To determine if voluntary alcohol drinking and/or abstinence is associated with changes in NPC survival, mice were injected with BrdU just before the onset of 28 days of alcohol drinking, and the number of surviving cells was measured following 2 or 14 days of abstinence. Results showed that the number of BrdU-positive cells in the dentate gyrus of alcohol-exposed mice was unchanged following short-term or protracted abstinence as compared to water-only controls. Although the overall number of surviving NPCs was unchanged, it is possible that there was a change in the number of surviving cells that became neurons rather than glia. However, the data from triple-label immunofluorescence experiments, found no difference in the percentage of BrdU-positive cells that were colabeled with either GFAP or NeuN in the dentate gyrus of alcohol-exposed mice as compared with water-only controls. These data indicate that the abstinenceinduced depression-like behavior in the present study was not associated with changes in the survival rate or phenotype of cells born before the onset of drinking. Thus, alcohol-induced changes in the survival of NPCs may require higher doses of alcohol than those that are achieved by voluntary drinking in mice.

Because it is known that factors that precipitate depression, such as stress and increased glucocorticoids, decrease hippocampal neurogenesis (Mirescu and Gould, 2006) and that antidepressants increase hippocampal neurogenesis (Malberg and Blendy, 2005; Malberg et al, 2000; Santarelli et $a l, 2003)$, we sought to determine if antidepressant treatment is effective in preventing abstinence-induced impairments in hippocampal neurogenesis that occur in parallel with depression-like behavior. Chronic treatment with the antidepressant desipramine during 14 days of abstinence following alcohol drinking prevented the decrease in the number of immature neurons, as well as the number of proliferating cells in the dentate gyrus. Although the decrease in proliferating cells was smaller in the second experiment relative to the first, this effect was because of lower raw data control values in the second experiment. We hypothesize that decreased proliferation in the control animals in the second experiment could be because of the effects of daily injections. It is worth noting that 14 days of desipramine administration had no effect on hippocampal neurogenesis in water-drinking mice as measured by PCNA and DCX immunohistochemistry. These data suggest that chronic desipramine treatment did not simply cause an overall increase in neurogenesis, but rather prevented abstinence-induced decreases in hippocampal neurogenesis.

The concomitant increase in DCX and PCNA immunoreactivity suggests that blockade of abstinence-induced depression-like behavior by desipramine may have been 
mediated by changes in multiple phases of hippocampal neurogenesis. Evidence indicates that NPCs express PCNA during and up to 4 days after the $S$ phase of the cell cycle (Mandyam et al, 2007); however, DCX expression peaks in the dentate gyrus between 1 and 21 days after the $S$ phase when NPC differentiation is occurring (Brown et al, 2003). Immunohistochemical studies of PCNA and DCX performed on a single day, therefore, are likely labeling mostly distinct populations of new cells. Thus, it is not clear from the present study if antidepressant treatment specifically protected against the abstinence-induced reduction in NPC proliferation or enhanced survival of post-proliferative cells born during the abstinence phase, either or both of which would lead to an increase in new neurons. Alternatively, it is also plausible that protection against the abstinenceinduced reduction in the number of new neurons by desipramine may have been conferred by a compensatory burst in NPC proliferation, which has been reported to occur 7 days after withdrawal from binge injection of alcohol (Nixon and Crews, 2004). These potential alternatives could be addressed in future studies that further elucidate the time course of changes in various phases of neurogenesis during abstinence from alcohol drinking. In either case, it appears from the present study that chronic antidepressant treatment protects against abstinence-induced reductions in both NPC proliferation and development of new neurons.

Although there is no single neurobiological mechanism that accounts for the behavioral pathologies associated with alcoholism or depression, converging evidence suggests that alcoholism and depression (and perhaps their cooccurrence) may share common molecular mechanisms of action. For example, chronic alcohol exposure reduces cAMP response element-binding protein (CREB) activity in the dentate gyrus (Bison and Crews, 2003). Reductions in CREB activity and function can occur during acute and protracted alcohol withdrawal and are associated with negative mood states, such as anxiety (reviewed by (Pandey, 2003)). By contrast, a variety of antidepressant drugs increase levels of CREB mRNA in the hippocampus (Nibuya et al, 1996). Viral overexpression of CREB in the dentate gyrus of the hippocampus also results in less depressionlike behavior in both the FST and learned helplessness tests (Chen et al, 2001). Accordingly, alcohol withdrawal is associated with reduced expression of CREB-target genes including brain-derived neurotrophic factor (BDNF) in the dentate gyrus (Tapia-Arancibia et al, 2001) whereas several different antidepressant drugs, including desipramine which was used in the present study, increase BDNF mRNA in the hippocampus (Nibuya et al, 1995). Moreover, chronic alcohol reduces hippocampal neurogenesis (Nixon and Crews, 2002) but the behavioral effects of antidepressant medications may require hippocampal neurogenesis(Santarelli et al, 2003). These and other findings have led to emerging theories that implicate a CREB-BDNF-neurogenesis pathway in both the etiology of depression and antidepressant efficacy (Duman et al, 2001; Malberg et al, 2000; Thomas and Peterson, 2003). Overall, CREB and BDNF activity in the dentate gyrus appear to be important mediators of antidepressant efficacy and raise the hypothesis that decreases in $\mathrm{p}$-CREB, such as those that occur after chronic alcohol, have the potential to induce behavioral despair and reductions in neurogenesis as seen in the present study.

Several features of the present study merit further discussion. First, although the data presented in this study suggest that depression-like behavior and related neuroadaptations emerge during abstinence following chronic drinking, it is worth mentioning that no single animal model of depression is sufficient to characterize the human condition of depression. In these experiments, we sought to characterize changes in affective behavior at a single time point during abstinence, which limited the number and type of behavioral measures we were able to conduct. Thus, it will be important in future studies to utilize other validated rodent behavioral tests of anxiety- and depression-like behavior to confirm and extend the present results. Second, it is worth noting that a $300 \mathrm{mg} / \mathrm{kg}$ dose of BrdU was chosen to examine NPC survival based on a published method (Cameron and McKay, 2001), which suggested that this dose labels all cells in the $S$ phase in the rat. However, a recent publication (Mandyam et al, 2007) has demonstrated that $150 \mathrm{mg} / \mathrm{kg}$ is sufficient to label all cells in the S phase in the mouse. Thus, we cannot rule out the possibility that our BrdU injection regimen caused toxicity to dividing cells, especially in combination with subsequent alcohol consumption; however, as no differences were found in the number of BrdU-labeled cells between any groups, we feel this probably did not contribute significantly to our results. Finally, our results showing that desipramine did not alter FST performance in or neurogenesis in control mice are somewhat surprising. Another study demonstrated that chronic desipramine treatment increases neurogenesis and decreases depression-like behavior in control mice; however, that study used utilized twice-daily administration of $12.5 \mathrm{mg} / \mathrm{kg}$ desipramine (Gur et al, 2007), indicating that a higher dose may have produced changes in our control animals. Additionally, although acute desipramine treatment has been shown to reduce immobility in the FST (Lucki et al, 2001), we did not administer desipramine on the day of the test. Our results are similar to those found by MacQueen et al (2003), showing that 14 days administration of desipramine at the same dose used in the current study $(15 \mathrm{mg} / \mathrm{kg})$ and not administered on the day of testing reduced immobility in the FST in mice in which depression had been induced, but not in control mice.

In conclusion, alcoholism and depression are two devastating disorders that commonly co-occur. Emerging evidence indicates that alcohol has detrimental effects on molecular pathways that may be involved in the pathophysiology of depression. Important clinical evidence indicates that depression that emerges during abstinence has a greater negative impact on relapse rates than pre-existing depression. Preclinical studies on this topic are lacking. To address this need, we have developed and validated a novel model of alcohol drinking-induced depression-like behavior in mice. The data presented here lend further support to the hypothesis that hippocampal neurogenesis is related to depression, as well as antidepressant efficacy. We show that abstinence following chronic alcohol drinking leads to a decrease in adult hippocampal neurogenesis at a time when depression-like behavior is also evident. Antidepressant treatment during abstinence prevents both the decrease in new neurons and the depression-like behavior, suggesting 
a mechanistic link. Given that new neurons constitute $6 \%$ of the total granule cells in the hippocampus, neurogenesis is crucial for hippocampal function (Cameron and McKay, 2001) and of potential importance to the etiology and treatment of alcoholism and comorbid depression.

\section{ACKNOWLEDGEMENTS}

This work was supported by Grants AA016629 and AA011605 to CWH, AA06069 to FTC, and AA016043 to JRS from the National Institute on Alcohol Abuse and Alcoholism, and by the Bowles Center for Alcohol Studies.

\section{DISCLOSURE/CONFLICT OF INTEREST}

We declare that, except for income received from our primary employer, no financial support or compensation has been received from any individual or corporate entity over the past 3 years for research or professional service and there are no personal financial holdings that could be perceived as constituting a potential conflict of interest.

\section{REFERENCES}

Aberg E, Hofstetter CP, Olson L, Brene S (2005). Moderate ethanol consumption increases hippocampal cell proliferation and neurogenesis in the adult mouse. Int J Neuropsychopharmacol 8: $557-567$.

Baldwin HA, Rassnick S, Rivier J, Koob GF, Britton KT (1991). CRF antagonist reverses the 'anxiogenic' response to ethanol withdrawal in the rat. Psychopharmacology (Berl) 103: 227-232.

Bison S, Crews F (2003). Alcohol withdrawal increases neuropeptide Y immunoreactivity in rat brain. Alcohol Clin Exp Res 27: 1173-1183.

Brown JP, Couillard-Despres S, Cooper-Kuhn CM, Winkler J, Aigner L, Kuhn HG (2003). Transient expression of doublecortin during adult neurogenesis. J Comp Neurol 467: 1-10.

Cameron HA, Gould E (1994). Adult neurogenesis is regulated by adrenal steroids in the dentate gyrus. Neuroscience 61: 203-209.

Cameron HA, McKay RD (2001). Adult neurogenesis produces a large pool of new granule cells in the dentate gyrus. J Comp Neurol 435: 406-417.

Carlezon Jr WA, Duman RS, Nestler EJ (2005). The many faces of CREB. Trends Neurosci 28: 436-445.

Celis JE, Madsen P, Celis A, Nielsen HV, Gesser B (1987). Cyclin (PCNA, auxiliary protein of DNA polymerase delta) is a central component of the pathway(s) leading to DNA replication and cell division. FEBS Lett 220: 1-7.

Chen AC, Shirayama Y, Shin KH, Neve RL, Duman RS (2001). Expression of the cAMP response element binding protein (CREB) in hippocampus produces an antidepressant effect. Biol Psychiatry 49: 753-762.

Costall B, Kelly ME, Naylor RJ (1988). The anxiolytic and anxiogenic actions of ethanol in a mouse model. J Pharm Pharmacol 40: $197-202$.

Couillard-Despres S, Winner B, Schaubeck S, Aigner R, Vroemen $\mathrm{M}$, Weidner $\mathrm{N}$ et al (2005). Doublecortin expression levels in adult brain reflect neurogenesis. Eur J Neurosci 21: 1-14.

Crews FT, Nixon K (2003). Alcohol, neural stem cells, and adult neurogenesis. Alcohol Res Health 27: 197-204.

Crews FT, Nixon K, Wilkie ME (2004). Exercise reverses ethanol inhibition of neural stem cell proliferation. Alcohol 33: 63-71.

Cryan JF, Valentino RJ, Lucki I (2005). Assessing substrates underlying the behavioral effects of antidepressants using the modified rat forced swimming test. Neurosci Biobehav Rev 29 547-569.

Dalvi A, Lucki I (1999). Murine models of depression. Psychopharmacology (Berl) 147: 14-16.

Dranovsky A, Hen R (2006). Hippocampal neurogenesis: regulation by stress and antidepressants. Biol Psychiatry 59: 1136-1143.

Duman RS, Malberg J, Nakagawa S (2001). Regulation of adult neurogenesis by psychotropic drugs and stress. J Pharmacol Exp Ther 299: 401-407.

Duman RS, Malberg J, Nakagawa S, D’Sa C (2000). Neuronal plasticity and survival in mood disorders. Biol Psychiatry 48: 732-739.

Duman RS, Malberg J, Thome J (1999). Neural plasticity to stress and antidepressant treatment. Biol Psychiatry 46: 1181-1191.

Gage FH (2002). Neurogenesis in the adult brain. J Neurosci 22: 612-613.

Garbutt JC, West SL, Carey TS, Lohr KN, Crews FT (1999). Pharmacological treatment of alcohol dependence: a review of the evidence. JAMA 281: 1318-1325.

Grant BF (1995). Comorbidity between DSM-IV drug use disorders and major depression: results of a national survey of adults. J Subst Abuse 7: 481-497.

Greenfield SF, Weiss RD, Muenz LR, Vagge LM, Kelly JF, Bello LR et al (1998). The effect of depression on return to drinking: a prospective study. Arch Gen Psychiatry 55: 259-265.

Gregus A, Wintink AJ, Davis AC, Kalynchuk LE (2005). Effect of repeated corticosterone injections and restraint stress on anxiety and depression-like behavior in male rats. Behav Brain Res 156: 105-114.

Gur TL, Conti AC, Holden J, Bechtholt AJ, Hill TE, Lucki I et al (2007). cAMP response element-binding protein deficiency allows for increased neurogenesis and a rapid onset of antidepressant response. J Neurosci 27: 7860-7868.

Hasin D, Liu X, Nunes E, McCloud S, Samet S, Endicott J (2002). Effects of major depression on remission and relapse of substance dependence. Arch Gen Psychiatry 59: 375-380.

He J, Nixon K, Shetty AK, Crews FT (2005). Chronic alcohol exposure reduces hippocampal neurogenesis and dendritic growth of newborn neurons. Eur J Neurosci 21: 2711-2720.

Hebb DO (1949). The Organization of Behavior. Wiley: New York.

Henn FA, Vollmayr B (2004). Neurogenesis and depression: etiology or epiphenomenon? Biol Psychiatry 56: 146-150.

Herrera DG, Yague AG, Johnsen-Soriano S, Bosch-Morell F, Collado-Morente L, Muriach M et al (2003). Selective impairment of hippocampal neurogenesis by chronic alcoholism: protective effects of an antioxidant. Proc Natl Acad Sci USA 100: 7919-7924.

Hodge CW, Mehmert KK, Kelley SP, McMahon T, Haywood A, Olive MF et al (1999). Supersensitivity to allosteric GABA(A) receptor modulators and alcohol in mice lacking PKCepsilon. Nat Neurosci 2: 997-1002.

Hodge CW, Raber J, McMahon T, Walter H, Sanchez-Perez AM, Olive MF et al (2002). Decreased anxiety-like behavior, reduced stress hormones, and neurosteroid supersensitivity in mice lacking protein kinase Cepsilon.[comment]. J Clin Invest 110: 1003-1010.

Hwang BH, Kunkler PE, Tarricone BJ, Hingtgen JN, Nurnberger Jr JI (1999). Stress-induced changes of norepinephrine uptake sites in the locus coeruleus of C57BL/6J and DBA/2J mice: a quantitative autoradiographic study using [3H]-tomoxetine. Neurosci Lett 265: 151-154.

Jacobs BL, Praag H, Gage FH (2000). Adult brain neurogenesis and psychiatry: a novel theory of depression. Mol Psychiatry 5: 262-269.

Johnson SA, Fournier NM, Kalynchuk LE (2006). Effect of different doses of corticosterone on depression-like behavior and HPA axis responses to a novel stressor. Behav Brain Res 168 280-288. 
Joshi D, Naidu PS, Singh A, Kulkarni SK (2005). Protective effect of quercetin on alcohol abstinence-induced anxiety and convulsions. J Med Food 8: 392-396.

Kempermann G (2002). Why new neurons? Possible functions for adult hippocampal neurogenesis. J Neurosci 22: 635-638.

Kessler RC, Crum RM, Warner LA, Nelson CB, Schulenberg J, Anthony JC (1997). Lifetime co-occurrence of DSM-III-R alcohol abuse and dependence with other psychiatric disorders in the National Comorbidity Survey. Arch Gen Psychiatry 54: 313-321.

Kliethermes CL (2005). Anxiety-like behaviors following chronic ethanol exposure. Neurosci Biobehav Rev 28: 837-850.

Kliethermes CL, Cronise K, Crabbe JC (2004). Anxiety-like behavior in mice in two apparatuses during withdrawal from chronic ethanol vapor inhalation. Alcohol Clin Exp Res 28: 1012-1019.

Krude T (1999). Chromatin replication: finding the right connection. Curr Biol 9: R394-R396.

Le Fauve CE, Litten RZ, Randall CL, Moak DH, Salloum IM, Green AI (2004). Pharmacological treatment of alcohol abuse/ dependence with psychiatric comorbidity. Alcohol Clin Exp Res 28: $302-312$.

Lucki I, Dalvi A, Mayorga AJ (2001). Sensitivity to the effects of pharmacologically selective antidepressants in different strains of mice. Psychopharmacology (Berl) 155: 315-322.

Lynskey MT (1998). The comorbidity of alcohol dependence and affective disorders: treatment implications. Drug Alcohol Depend 52: 201-209.

MacQueen GM, Ramakrishnan K, Ratnasingan R, Chen B, Young LT (2003). Desipramine treatment reduces the long-term behavioural and neurochemical sequelae of early-life maternal separation. Int J Neuropsychopharmacol 6: 391-396.

Malberg JE, Blendy JA (2005). Antidepressant action: to the nucleus and beyond. Trends Pharmacol Sci 26: 631-638.

Malberg JE, Duman RS (2003). Cell proliferation in adult hippocampus is decreased by inescapable stress: reversal by fluoxetine treatment. Neuropsychopharmacology 28: 1562-1571.

Malberg JE, Eisch AJ, Nestler EJ, Duman RS (2000). Chronic antidepressant treatment increases neurogenesis in adult rat hippocampus. J Neurosci 20: 9104-9110.

Mandyam CD, Harburg GC, Eisch AJ (2007). Determination of key aspects of precursor cell proliferation, cell cycle length and kinetics in the adult mouse subgranular zone. Neuroscience 146: $108-122$.

Miller HL, Delgado PL, Salomon RM, Berman R, Krystal JH, Heninger GR et al (1996). Clinical and biochemical effects of catecholamine depletion on antidepressant-induced remission of depression. Arch Gen Psychiatry 53: 117-128.

Ming GL, Song H (2005). Adult neurogenesis in the mammalian central nervous system. Annu Rev Neurosci 28: 223-250.

Mirescu C, Gould E (2006). Stress and adult neurogenesis. Hippocampus 16: 233-238.

Moy SS, Knapp DJ, Criswell HE, Breese GR (1997). Flumazenil blockade of anxiety following ethanol withdrawal in rats. Psychopharmacology (Berl) 131: 354-360.

Mueller TI, Lavori PW, Keller MB, Swartz A, Warshaw M, Hasin D et al (1994). Prognostic effect of the variable course of alcoholism on the 10-year course of depression. Am J Psychiatry 151: 701-706.

Nibuya M, Morinobu S, Duman RS (1995). Regulation of BDNF and trkB mRNA in rat brain by chronic electroconvulsive seizure and antidepressant drug treatments. J Neurosci 15: 7539-7547.

Nibuya M, Nestler EJ, Duman RS (1996). Chronic antidepressant administration increases the expression of cAMP response element binding protein (CREB) in rat hippocampus. J Neurosci 16: $2365-2372$.

Nixon K (2006). Alcohol and adult neurogenesis: Roles in neurodegeneration and recovery in chronic alcoholism. Hippocampus 16: 287-295.
Nixon K, Crews FT (2002). Binge ethanol exposure decreases neurogenesis in adult rat hippocampus. J Neurochem 83: 10871093.

Nixon K, Crews FT (2004). Temporally specific burst in cell proliferation increases hippocampal neurogenesis in protracted abstinence from alcohol. J Neurosci 24: 9714-9722.

Ostacher MJ (2007). Comorbid alcohol and substance abuse dependence in depression: impact on the outcome of antidepressant treatment. Psychiatr Clin North Am 30: 69-76.

Pandey SC (2003). Anxiety and alcohol abuse disorders: a common role for CREB and its target, the neuropeptide $\mathrm{Y}$ gene. Trends Pharmacol Sci 24: 456-460.

Pandey SC, Zhang D, Mittal N, Nayyar D (1999). Potential role of the gene transcription factor cyclic AMP-responsive element binding protein in ethanol withdrawal-related anxiety. J Pharmacol Exp Ther 288: 866-878.

Paxinos G, Franklin KBJ (2001). The Mouse Brain in Sterotaxic Coordinates, 2nd edn, Academic Press: New York.

Pettinati HM (2004). Antidepressant treatment of co-occurring depression and alcohol dependence. Biol Psychiatry 56: 785-792.

Plaznik A, Tamborska E, Hauptmann M, Bidzinski A, Kostowski W (1988). Brain neurotransmitter systems mediating behavioral deficits produced by inescapable shock treatment in rats. Brain Res 447: 122-132.

Pohorecky LA (1976). Withdrawal from ethanol: simple quantitative behavioral tests for its evaluation. Psychopharmacology (Berl) 50: 125-129.

Popken GJ, Farel PB (1997). Sensory neuron number in neonatal and adult rats estimated by means of stereologic and profilebased methods. J Comp Neurol 386: 8-15.

Porsolt RD, Bertin A, Jalfre M (1977). Behavioral despair in mice: a primary screening test for antidepressants. Archives Internationales de Pharmacodynamie et de Therapie 229: 327-336.

Prediger RD, da Silva GE, Batista LC, Bittencourt AL, Takahashi RN (2006). Activation of adenosine Al receptors reduces anxiety-like behavior during acute ethanol withdrawal (hangover) in mice. Neuropsychopharmacology 31: 2210-2220.

Prince CR, Anisman H (1984). Acute and chronic stress effects on performance in a forced-swim task. Behav Neural Biol 42: 99-119.

Rao MS, Shetty AK (2004). Efficacy of doublecortin as a marker to analyse the absolute number and dendritic growth of newly generated neurons in the adult dentate gyrus. Eur J Neurosci 19: 234-246.

Rasmussen DD, Mitton DR, Green J, Puchalski S (2001). Chronic daily ethanol and withdrawal: behavioral changes during prolonged abstinence. Alcohol Clin Exp Res 25: 999-1005.

Rassnick S, Heinrichs SC, Britton KT, Koob GF (1993). Microinjection of a corticotropin-releasing factor antagonist into the central nucleus of the amygdala reverses anxiogenic-like effects of ethanol withdrawal. Brain Res 605: 25-32.

Santarelli L, Saxe M, Gross C, Surget A, Battaglia F, Dulawa S et al (2003). Requirement of hippocampal neurogenesis for the behavioral effects of antidepressants. Science 301: 805-809.

Schuckit MA, Tipp JE, Bergman M, Reich W, Hesselbrock VM, Smith TL (1997). Comparison of induced and independent major depressive disorders in 2,945 alcoholics. Am J Psychiatry 154: 948-957.

Snyder JS, Kee N, Wojtowicz JM (2001). Effects of adult neurogenesis on synaptic plasticity in the rat dentate gyrus. J Neurophysiol 85: 2423-2431.

Sparta DR, Fee JR, Knapp DJ, Breese GR, Thiele TE (2007). Elevated anxiety-like behavior following ethanol exposure in mutant mice lacking neuropeptide Y (NPY). Drug Alcohol Depend 90: 297-300.

Tanapat P, Hastings NB, Rydel TA, Galea LA, Gould E (2001). Exposure to fox odor inhibits cell proliferation in the 
hippocampus of adult rats via an adrenal hormone-dependent mechanism. J Comp Neurol 437: 496-504.

Tapia-Arancibia L, Rage F, Givalois L, Dingeon P, Arancibia S, Beauge F (2001). Effects of alcohol on brain-derived neurotrophic factor mRNA expression in discrete regions of the rat hippocampus and hypothalamus. J Neurosci Res 63: 200-208.

Thomas RM, Peterson DA (2003). A neurogenic theory of depression gains momentum. Mol Interv 3: 441-444.

Thome J, Sakai N, Shin K, Steffen C, Zhang YJ, Impey S et al (2000). cAMP response element-mediated gene transcription is upregulated by chronic antidepressant treatment. J Neurosci 20 4030-4036.

Warner-Schmidt JL, Duman RS (2006). Hippocampal neurogenesis: opposing effects of stress and antidepressant treatment. Hippocampus 16: 239-249.

Yew DT, Sha O, Li WW, Lam TT, Lorke DE (2001). Proliferation and apoptosis in the epithelium of the developing human cornea and conjunctiva. Life Sci 68: 2987-3003.

Zhao Y, Weiss F, Zorrilla EP (2007). Remission and resurgence of anxiety-like behavior across protracted withdrawal stages in ethanol-dependent rats. Alcohol Clin Exp Res 31: 1505-1515. 